\title{
Stage IV Cervical Cancer FIGO 2018
}

National Cancer Institute

\section{Source}

National Cancer Institute. Stage IV Cervical Cancer FIGO 2018. NCI Thesaurus. Code C162245.

The cervical carcinoma has extended beyond the true pelvis or has involved (biopsy proven) the mucosa of the bladder or rectum. (A bullous edema, as such, does not permit a case to be allotted to Stage IV). (FIGO 2018) 